\title{
CHEMICAL CONSTITUENTS FROM THE LEAVES OF Synsepalum dulcificum
}

\author{
C. Y. Chen*, Y. D. Wang, and H. M. Wang
}

UDC 547.918

Synsepalum dulcificum Daniell (Sapotaceae) is an evergreen shrub native to tropical West Africa, and the fruits, and red berries have the property of modifying sour taste into sweet taste remarkably. Interestingly, the active material of the berry is the protein, miraculin, which has no taste in itself. The sweetness intensity induced by $0.02 \mathrm{M}$ citric acid after $0.4 \mathrm{M}$ purified miraculin solution is held in the mouth is equivalent to that of about $0.3 \mathrm{M}$ sucrose. This value is equal to the maximum sweetness induced by miraculin [1].

The specimen of $S$. dulcificum was collected from Kaohsiung County, Taiwan, October 2007. A voucher specimen was identified by Dr. Fu-Yuan Lu (Department of Forestry and Natural Resources, College of Agriculture, National Chiayi University) and was deposited in the School of Medical and Health Science, The Fooyin University, Kaohsiung County, Taiwan. The stems $(5.0 \mathrm{~kg})$ of $S$. dulcificum were extracted repeatedly with $\mathrm{MeOH}$ at room temperature for $24-48 \mathrm{~h}$. The $\mathrm{MeOH}$ extract was dried and evaporated to leave a viscous residue (102.3 g). The residue was placed on a silica gel column and eluted with $\mathrm{CHCl}_{3}$ gradually enriched with $\mathrm{MeOH}$ to afford 10 fractions. Fraction 3 was rechromatographed on silica gel ( $n$-hexane-EtOAc, 20:1) and recrystallized from EtOAc to give a mixture of $\beta$-sitosterol (1) and stigmasterol (2) (317.2 mg). Fraction 4, eluted from $n$-hexane-EtOAc (1:2), was further chromatographed on silica gel elution with EtOAc-MeOH (15:1) and recrystallized from acetone to give pheophytin-a (3) (21.4 mg) and pheophytin-b (4) (15.8 mg), respectively. Fraction 5 was purified by silica gel chromatography (EtOAc-MeOH, 40:1) to give colorless needles of lupeol (5) (321.5 mg). Fraction 6 was purified by silica gel chromatography (EtOAc-MeOH, 8:1) to give colorless needles of lupenone (6) (51.4 mg) and lupeol acetate $(7)(21.1 \mathrm{mg})$. Fraction 7 was purified by silica gel chromatography $\left(\mathrm{CHCl}_{3}-\mathrm{MeOH}, 40: 1\right)$ to give $\alpha$-tocopheryl quinone (8) (52.4 mg).

The $\mathrm{MeOH}$ extract of its leaves was subjected to solvent partitioning and chromatographic separation to afford five pure substances. The chemical constituents of the leaves of $S$. dulcificum were separated with column chromatography. Eight compounds, including, a mixture of $\beta$-sitosterol (1) and stigmasterol (2) [2], pheophytin-a (3) [3], pheophytin-b (4) [3], lupeol (5) [4], lupenone (6) [5], lupeol acetate (7) [6], and $\alpha$-tocopheryl quinone (8) [7], were isolated from the leaves of $S$. dulcificum. All of these compounds were found for the first time from this plant.

\section{ACKNOWLEDGMENT}

This investigation was supported by a grant from the National Science Council of the Republic of China (NSC 97-2320-B-242-002-MY3).

\section{REFERENCES}

1. K. Kurihara and L. M. Beidler, Nature, 222, 1176 (1969).

2. T. J. Hsieh, Y. C. Wu, S. C. Chen, C. S. Huang, and C. Y. Chen, J. Chin. Chem. Soc., 51, 869 (2004).

3. Y. Nakatani, G. Ourisson, and J. P. Beck, Chem. Pharm. Bull., 29, 2261 (1981).

4. H. Ishii, I. S. Chen, M. Akaike, T. Ishikawa, and S. T. Lu, Yakugaku Zasshi, 102, 182 (1982).

5. A. A. L. Gunatilaka, S. Sotheeswaran, B. Sriyani, and S. Balasubramaniam, Planta Med., 43, 309 (1981).

6. Y. L. Chow and H. H. Quon, Phytochemistry, 9, 1151 (1970).

7. I. L. Tsai, Y. F. Jeng, B. Jayaprakasam, and I. S. Chen, Chin. Pharm. J., 53, 291 (2001).

School of Medical and Heath Science, The Fooyin University, Ta-Liao, Kaohuing, Taiwan 831, R. O. C., fax: +886 77863667 , e-mail: xx377@mail.fy.edu.tw. Published in Khimiya Prirodnykh Soedinenii, No. 3, p. 416, May-June, 2010. Original article submitted December 3, 2008. 